\title{
Setting of Disease Contact
}

National Cancer Institute

\section{Source}

National Cancer Institute. Setting of Disease Contact. NCI Thesaurus. Code C102708.

The environment within which the person may have come into contact with a disease carrier, or played the role of a disease carrier. 